\title{
Mycoplasmas recovered from patients with urethritis
}

\author{
DAVID A. HILL*†, ROBERT N. PHILIPł, ASTON B. GREAVES $\$$, AND \\ ROBERT H. PURCELL†
}

From the + Laboratory of Infectious Diseases, National Institute of Allergy and Infectious Diseases, Bethesda, Maryland, the $\ddagger$ Rocky Mountain Laboratory, National Institute of Allergy and Infectious Diseases, Hamilton, Montana, and the \$Venereal Disease Control Division, District of Columbia Department of Health, Washington, D.C., U.S.A.

Of the many organisms isolated from patients with non-gonococcal urethritis (NGU) and post-gonococcal urethritis (PGU), mycoplasmas have received considerable attention. Recovery of mycoplasmas from urethral discharge in males was first reported by Smith (1942). Large-colony mycoplasmas, particularly Mycoplasma hominis, have been isolated frequently from cases of NGU. Studies investigating the role of $M$. hominis in NGU have indicated that it is probably associated with sexual promiscuity rather than disease (Hayflick and Chanock, 1965; Taylor-Robinson, Addey, Hare, and Dunlop, 1969). In contrast, the role of $T$-strain mycoplasmas in NGU and PGU is unclear.

Several investigators have reported an association between T-strain mycoplasmas and NGU (Shepard, 1959; Ford, Rasmussen, and Minken, 1962; Ford, and Du Vernet, 1966; Csonka, Williams, and Corse, 1966; Jansson, Lassus, Stubb, and Tuuri, 1971); others have failed to detect such an association (Ingham, MacFarlane, Hale, Selkon, and Codd, 1966; Black and Rasmussen, 1968; Hare, Dunlop, and Taylor-Robinson, 1969; Fowler and Leeming, 1969; Haas, Dorfman, and Sacks, 1971).

This study was undertaken to examine the serological characteristics of large colony and $\mathrm{T}$-strain mycoplasmas recovered from patients with different types of urethritis. In addition, media with special supplements were employed in an attempt to isolate new species of genital mycoplasmas from patients with urethritis.

\section{Material}

MEDIA

Hayflick's medium (Chanock, Hayflick, and Barile, 1962)

Received for publication, March 7, 1973

Address for reprints: Dr. R. H. Purcell National Institute of Health, National Institute of Allergy and Infectious Diseases, Laboratory of Infectious Diseases, Building 7 Room 202, Bethesda, Maryland 20014, U.S.A.

*Present address: Dr. D. A. Hill, Massachusetts General Eye-Ear Infirmary, Boston, Mass., U.S.A. was used for the cultivation of mycoplasmas. It consisted of seven parts PPLO agar or broth, two parts unheated horse serum, one part 25 per cent. yeast extract, and aqueous penicillin $G$ at a concentration of 1,000 units per $\mathrm{ml}$. Thallium acetate (final concentration of $1: 2,000$ ) was added to those media which were not used to cultivate T-strain mycoplasmas. Phenol red $(0.002$ per cent.), added to broth media, served as an indicator of $\mathrm{pH}$ change. PPLO agar plates consisted of $5 \mathrm{ml}$. agar medium in $15 \times 60 \mathrm{~mm}$. disposable plastic Petri plates. Plates with four variations of the agar medium were prepared:

(1) Standard PPLO agar, as described above;

(2) PPLO agar without thallium;

(3) Cysteine PPLO agar-standard PPLO agar with $0 \cdot 1$ per cent. cysteine;

(4) DNA PPLO agar-standard PPLO agar with 0.02 per cent. bovine sperm DNA.

Four variations of the broth medium were prepared by adding substrates and supplements to the basic medium as follows:

(1) Urea broth-1 per cent. urea, free of tiallium, pH $6 \cdot 0$;

(2) Cysteine broth -0.1 per cent. cysteine, 0.1 per cent. arginine, 0.1 per cent. urea, 0.1 per cent. glucose with thallium added, $\mathrm{pH} 7 \cdot 0$;

(3) DNA broth -0.02 per cent. bovine sperm DNA, $0 \cdot 1$ per cent. arginine, $0 \cdot 1$ per cent. urea, 0.1 per cent. glucose with thallium $\mathrm{pH} 7 \cdot 0$;

(4) Arginine broth-1 per cent. arginine with thallium $\mathrm{pH} 7 \cdot 0$.

Transport medium consisted of veal infusion broth with 0.5 per cent. bovine serum albumin. Such medium was found to be at least as satisfactory as mycoplasma medium for storage of mycoplasmas at $0-4^{\circ} \mathrm{C}$. M. hominis and $\mathrm{T}$-strain mycoplasmas stored in transport medium at $4^{\circ} \mathrm{C}$. retained full titre for at least $48 \mathrm{hrs}$.

REFERENCE STRAINS OF MYCOPLASMAS AND PREPARATION OF ANTISERUM

The characterization of $M$. hominis strains PG-21, DC-63, V-2785, and Botte used in this study, and the preparation of antisera to them, have been described previously (Edward and Freundt, 1956; Taylor-Robinson, Somerson, Turner, and Chanock, 1963). Strain PG-21 was a urethral isolate; the other $M$. hominis strains were recovered from the respiratory tract. T-strain mycoplasma T-960 was recovered from the urethra of a 
patient with NGU by Shepard (1966); Strains T-23, T-7, $\mathrm{T}-27, \mathrm{~T}-31, \mathrm{~T}-58, \mathrm{~T}-354$, and Cook were isolated from NGU patients by Ford (1967). Strains Bo-T, He-U, Sm-U, St-U, and Th-U were recovered from healthy young adult male prisoners by one of us (R.H.P.). Immunizing antigen was prepared from 7-day cultures of thrice-cloned T-strain mycoplasmas in Hayflick's medium without thallium acetate. The medium was initially adjusted to $\mathrm{pH} 6.0$ with IN $\mathrm{HCl}$. T-strain mycoplasma antigen was concentrated by centrifugation at 15,000 r.p.m. in a Sorvall Model RC-2 centrifuge with KSB-R continuous-flow system and SS-34 rotor. Pellets of mycoplasmas were re-suspended at 100 to 400 -fold concentrations in phosphate-buffered saline, $\mathrm{pH} 7 \cdot 2$, and stored at $-20^{\circ} \mathrm{C}$. until used. Rabbits were immunized according to the schedule for large colony mycoplasmas as described previously (Taylor-Robinson and others, 1963). Antiserum prepared in a similar manner to uninoculated Hayflick's medium did not inhibit the growth of large colony or T-strain mycoplasmas.

\section{Methods}

The study population, its clinical evaluation, and the method of obtaining and processing urethral and other specimens for culture have been described in detail elsewhere (Philip, Hill, Greaves, Gordon, Quan, Gerloff, and Thomas, 1971); they are described briefly herein.

The study was conducted at the Northwest Central Venereal Disease Clinic in the District of Columbia. Roughly 70 per cent. of the daily clinic census had gonorrhoea (GU) and 5 per cent. had NGU or PGU.

The study participants included persons attending the clinic between September 16, 1968, and November 15, 1968. Because of the heavy clinic load, clinical examinations were cursory and classification was based on diagnosis by four experienced clinic physicians.

Participants with NGU, PGU, or GU were selected at random from the clinic population as the laboratory work-load permitted. Patients diagnosed as having NGU generally had scanty urethral discharge which was negative for gonococci on microscopic examination. Diagnosis of GU was confirmed microscopically. Participants with PGU had persistent or recurrent gonococcusnegative urethritis after recent penicillin therapy for GU. All participants with NGU and PGU were males, because the diagnosis of GU was difficult without cultural confirmation in the female patient.

Specimens were obtained for isolation of mycoplasmas from the urethra of NGU, PGU, and GU patients, and from the cervix and urethra of NGU contacts. Isolation was attempted only from untreated patients except for the penicillin-treated PGU cases. Bacteriological loops and cotton-tipped applicators moistened in saline were used to collect exudate and epithelial cells from the cervical os and from up to $4 \mathrm{~cm}$. within the urethral meatus. Loops and swabs were rinsed in $2 \mathrm{ml}$. transport medium.

All specimens were transported in wet ice. Within $6 \mathrm{hrs}$ each specimen was diluted 1:4 with additional transport medium and inoculated into the media.

\section{MYCOPLASMA ISOLATION}

A $0.1 \mathrm{ml}$. aliquot of each specimen was inoculated onto each of three PPLO agar plates:

(1) Standard PPLO agar;

(2) Cysteine PPLO agar;

(3) DNA PPLO agar;

and also into three 1-dram vials, each containing $2.5 \mathrm{ml}$. of one of the following PPLO broth media:

(1) Urea broth;

(2) Cysteine broth;

(3) DNA broth.

After inoculation the agar plates were incubated at $37^{\circ} \mathrm{C}$. in an atmosphere of 5 per cent. carbon dioxide and 95 per cent. nitrogen. They were observed for 14 days for the presence of large colony mycoplasmas. Large colony mycoplasmas were identified with fluorescein-conjugated antiserum (Del Guidice, Robillard, and Carski, 1967). The broth media were incubated at $37^{\circ} \mathrm{C}$. and observed for a change in $\mathrm{pH}$ indicating growth of mycoplasmas. All broth cultures which developed a change in $\mathrm{pH}$ were passed to a second set of broth media to confirm growth and passed onto standard PPLO agar plates and PPLO agar plates free of thallium. The standard plates were incubated and observed as above. The plates free of thallium were incubated at $37^{\circ} \mathrm{C}$. in an atmosphere of 20 per cent. carbon dioxide and 80 per cent. nitrogen for 3 days, and then stained with Dienes' stain and examined for the presence of tiny mycoplasma colonies.

\section{SEROTYPIC STUDY OF MYCOPLASMAS}

The pattern of serological cross-reactivity of each isolated mycoplasma was determined by means of the metabolic inhibition (MI) test as previously described (Purcell, Taylor-Robinson, Wong, and Chanock, 1966a, b). A pool of each mycoplasma isolate was made in broth medium-T-strain mycoplasmas in urea broth, $M$. hominis in arginine broth. The mycoplasma isolates were not cloned.

\section{SEROLOGICAL STUDIES}

Serum was collected from each patient when he was seen initially and again 3 to 4 weeks later when possible. In those cases in which a mycoplasma was isolated and in which paired sera were available (for thirteen patients with T-strain isolations and five patients with $M$. hominis isolations), the paired sera were tested for antibody against the homologous organism by the MI technique. All serum pairs (48 of 86 cases: 23 from patients with NGU, four from patients with PGU, eight from NGU contacts, and thirteen from patients with GU) were tested for MI antibody to PG-21 and DC-63 strains of M. hominis and T-960 and T-23 T-strain mycoplasmas.

\section{Results}

Recovery of mycoplasmas

Only $M$. hominis and $\mathrm{T}$-strain mycoplasmas were isolated during the course of this study (Table I). $\mathrm{T}$-strain mycoplasmas were recovered almost twice 
TABLE I Mycoplasmas isolated from patients with urethritis

\begin{tabular}{|c|c|c|c|c|c|c|c|c|c|c|c|}
\hline & $\begin{array}{l}\text { No. of } \\
\text { patients } \\
\text { examined }\end{array}$ & \multicolumn{10}{|c|}{ No. yielding indicated mycoplasma } \\
\hline NGU & 36 & 16 & 44 & 8 & 22 & 3 & 8 & 19 & 53 & 11 & 31 \\
\hline PGU & 9 & 3 & 33 & 1 & 11 & 0 & & 3 & 33 & 1 & 11 \\
\hline NGU Contacts & 9 & 1 & 11 & 0 & & 0 & & 1 & 11 & 0 & \\
\hline Total & 86 & 28 & 33 & 14 & 16 & 5 & 6 & 33 & 38 & 19 & 22 \\
\hline
\end{tabular}

as frequently from patients with NGU (53 per cent.) as from patients with GU ( 31 per cent.); the isolation rate of T-strains from patients with PGU (33 per cent.) was approximately the same as that for those with GU (31 per cent.). The isolation rate of $M$. hominis was higher from NGU patients (31 per cent.) than from PGU patients (11 per cent.) or GU patients (22 per cent.). However, none of the differences in isolation rates were statistically significant, partly because the number of patients studied was small.

$T$-strains were recovered more frequently from urea broth (27 isolates from 86 cultures) than from cysteine $(19 / 86)$ or DNA broth $(22 / 86)$. M. hominis was recovered with similar frequency from all three broth media. The three agar media also were equally suitable for isolating $M$. hominis.

Serotypic characterization of mycoplasma isolates A serological profile of each $M$. hominis isolate was prepared by determining the extent to which it was inhibited in a MI test by antisera prepared to four strains of M. hominis (Table II). All four antisera inhibited the growth of the isolates, but the DC-63 strain of $M$. hominis appeared to be the most closely related to most of the strains tested; we did not observe significant differences in the pattern of reactivity of isolates from patients with different types of urethritis. When 17 of the $27 \mathrm{~T}$-strain isolates from patients with different types of urethritis were tested in a similar manner with antisera prepared to thirteen $\mathrm{T}$-strain mycoplasmas, diverse patterns of cross-reactivity were observed (Table III). Furthermore, there was no relationship between the pattern of reactivity of an isolate and the type of urethritis from which it was isolated. Sixteen of the seventeen T-strains tested, regardless of their association with urethritis, appeared to be related to strain T-58 and/or T-23; in addition, most of the isolates demonstrated varying degrees of relatedness to one or more of the other strains for which specific immune sera were available. In summary, serological heterogeneity was observed among urethral isolates

TABLE II Serological relationship of $\mathrm{M}$. hominis isolates from patients with urethritis to four well-characterized strains of M. hominis

\begin{tabular}{|c|c|c|c|c|c|c|c|c|c|c|c|c|c|c|}
\hline \multirow{3}{*}{$\begin{array}{l}\text { Specific } \\
\text { strain of } \mathrm{M} \text {. } \\
\text { hominis to } \\
\text { which anti- } \\
\text { serum was } \\
\text { prepared }\end{array}$} & \multicolumn{14}{|c|}{ Metabolic inhibition titre of specific antisera when tested against indicated $\mathbf{M}$. hominis strain } \\
\hline & \multirow[t]{2}{*}{$\begin{array}{l}\text { Homol- } \\
\text { ogous }\end{array}$} & \multicolumn{7}{|c|}{ Isolates from patients with NGU } & \multirow{2}{*}{$\begin{array}{l}\text { Isolate } \\
\text { from } \\
\text { patient } \\
\text { with } \\
P G U \\
008\end{array}$} & \multicolumn{5}{|c|}{ Isolates from patients with $G U$} \\
\hline & & $024^{\star \star}$ & 028 & $038 \star \star$ & 049 & 054 & $014 \star \star$ & 030 & & $012 \star \star$ & 062 & 073 & 083 & $087^{\star \star}$ \\
\hline DC-63 & $10,240 \star$ & 2,560 & 2,560 & 2,560 & 5,120 & 10,240 & 1,280 & 2,560 & 2,560 & 5,120 & 2,560 & 10,240 & 5,120 & 1,280 \\
\hline V2785 & 40,960 & 320 & 320 & 2,560 & 320 & 320 & 2,560 & 640 & 5,120 & 640 & 640 & 640 & 2,560 & 640 \\
\hline Botte & 81,920 & 160 & 80 & 320 & 320 & 320 & 80 & 1,280 & 160 & 160 & 320 & 1,280 & 160 & 160 \\
\hline PG-21 & 20,480 & 640 & 40 & 160 & 640 & 20 & 40 & 160 & 80 & 160 & 20 & 20 & 20 & 640 \\
\hline
\end{tabular}


TABLE III Serological relationship of $T$-strain mycoplasma isolates from patients with urethritis to thirteen well-characterized strains of T-mycoplasma

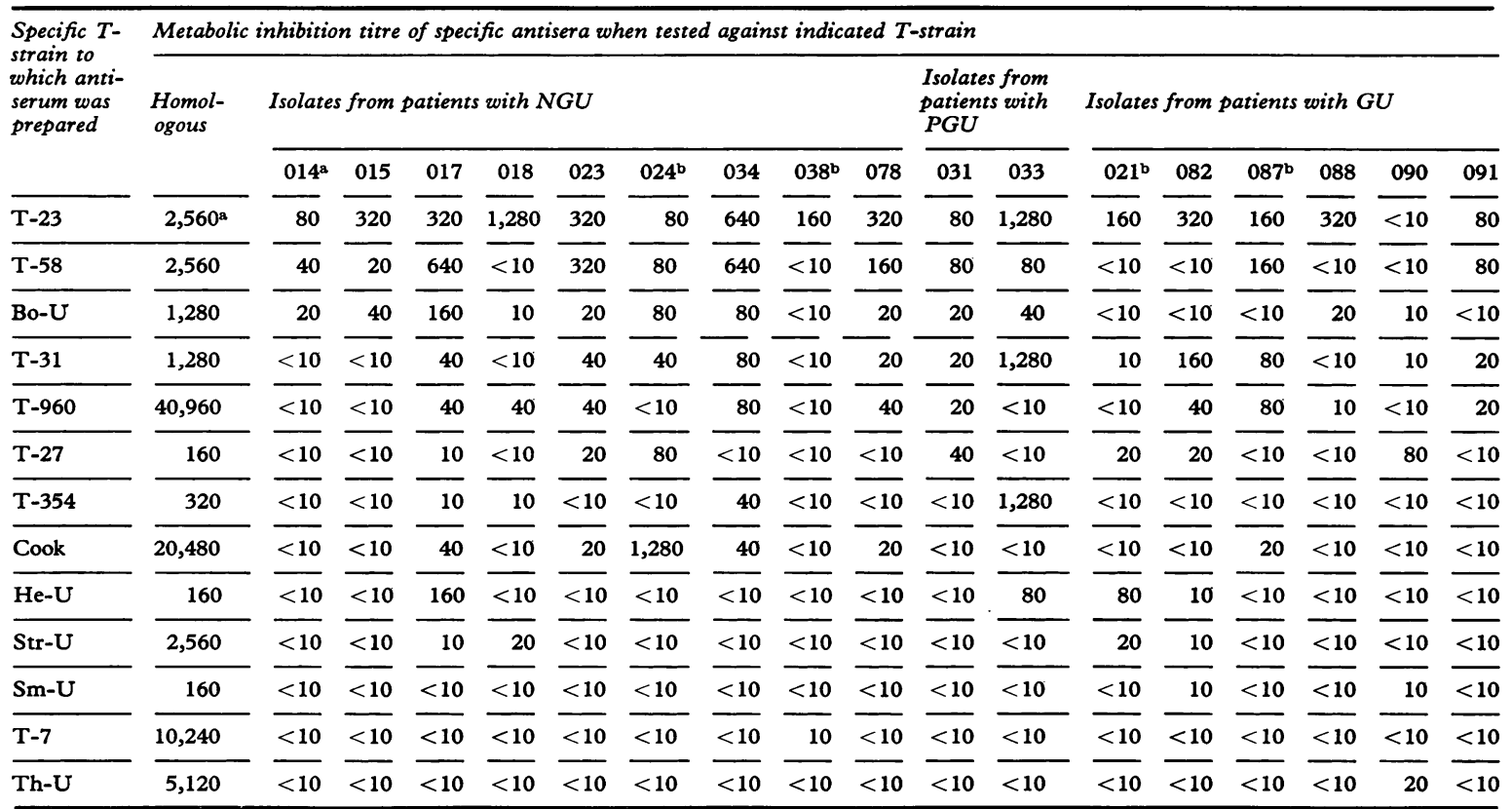

${ }^{a}$ All titres expressed as reciprocal of the highest dilution of serum which gave $50 \%$ reduction of colour change with 100 colour-changing units of mycoplasma.

both T-strains and M. hominis isolated from this patient.

of $M$. hominis and T-strain mycoplasmas, but there was ne pattern of heterogeneity characteristic of isolates from patients with any one type of urethritis.

\section{Sero-epidemiological characterization of patients}

'Nhen paired sera from 48 patients with NGU, PGU, or GU were tested for $\mathrm{MI}$ antibody to $M$. hominis strains PG-21 and DC 63 and T-strains $T-960$ and $T-23$, none of the paired sera demonstrated a significant (4-fold or greater) rise in antibody titre. However, it was observed that:

(a) None of the sera contained antibody $(<1: 2)$ to strain T-23;

(b) Thirty paired sera (63 per cent.) contained low stable titres of antibody to T-960 (1:2 to $1: 32)$;

(c) Twenty paired sera (42 per cent.) contained low stable titres of antibody to PG-21 (1:2 to $1: 8)$.

Paired sera from thirteen patients from whom $T$-strain mycoplasmas were isolated and paired sera from five patients from whom $M$. hominis was isolated were tested for MI antibody to the homologous mycoplasma; none of the sera contained such antibody $(<1: 2)$.
There did not appear to be a correlation between the presence of antibody to $M$. hominis or T-strains in the acute serum specimens and the recovery of mycoplasmas from the urethra, nor was there a relationship between the pattern of antibodies to mycoplasmas and the type of urethritis observed. However, the number of patients studied was not adequate for statistical analysis.

\section{Relationship between isolation of mycoplasmas and chlamydiae}

As part of another study, all specimens were tested for the presence of chlamydiae (Philip and others, 1971). The occurrence of mycoplasmas and/or chlamydiae in the urethra appeared to occur independently of each other (Table IV, overleaf). The findings are consistent with the conclusion that both types of organisms occurred independently in this population of patients with urethritis.

\section{Discussion}

Only $\mathrm{T}$-strain and $M$. hominis mycoplasmas were recovered from the urethra of patients in the present 
study. T-strains were recovered almost twice as frequently from patients with NGU as from patients with GU, a finding consistent with other reports (Ford and others, 1962; Shepard, Alexander, Lunceford, and Campbell, 1964; Csonka and others, 1966). Furthermore, the isolation rate of $T$-strains from patients with NGU or GU was within the range of isolation rates reported previously (Haas and others, 1971).

In an attempt to isolate mycoplasmas which might have requirements for in vitro growth not satisfied by standard PPLO broth, media supplemented with cysteine and/or DNA were used. The use of DNA as a supplement in mycoplasma medium was described by Edward and Fitzgerald (1952) for the more efficient isolation of bovine mycoplasmas. More recently it was used by Del Giudice (personal communication) to improve the growth of fastidious large colony mycoplasmas of human origin. Purcell (unpublished data) found that medium supplemented with cysteine was superior to unsupplemented medium for the growth of a laboratory-adapted strain of $M$. orale Type 1 but not for strains of $M$. hominis, $M$. salivarium, or $M$. orale Types 2 and 3. However, in the present study, medium supplemented with DNA and/or cysteine did not increase the isolation rate or lead to the isolation of any mycoplasmas which would not grow on standard media.

We did not study a group of patients free from venereal disease; however, previous studies have demonstrated a strong association between the isolation of mycoplasmas and frequent exposure to such disease. In a study of patients with venereal disease, selection of a suitable control group presents difficulties. The extent of venereal exposure is practically impossible to assess accurately, and the subjective symptoms expressed by patients with mild illness vary so greatly as to make strict exclusion of some degree of illness difficult. For these reasons groups of patients free from any complaints referable to the lower urogenital tract who had had similar exposure to venereal disease could not be identified. The use of patients with gonorrhoea as controls is far from ideal, since the effect of the gonococcal urethritis on the presence of mycoplasmas in the urethra is not known; however, these patients would be expected to match those with NGU in general exposure to venereal disease and socioeconomic status; healthy controls might not.

The T-strain and $M$. hominis mycoplasma isolates obtained from patients with NGU, PGU, and GU were quite heterogeneous in their serological composition, a finding consistent with previous studies of these mycoplasmas (Ford, 1967; Purcell, Wong, Chanock, Taylor-Robinson, Canchola, and Valdesuso, 1967; Purcell, Chanock, and Taylor-Robinson, 1969). We could not demcnstrate a pattern of serological reactivity characteristic of isolates obtained from any one type of urethritis studied. The isolates tested were not cloned; therefore it is possible that different serological variants may have become predominant in different isolate populations. However, previous studies demonstrated that all clones of $M$. hominis obtained from a first passage culture of this mycoplasma were serologically identical, whereas clones obtained from different isolates were serologically heterogeneous (Purcell and others, 1969). Thus, it is probable that the isolates tested in the present study were representative of the mycoplasmas recovered from the patients.

We could not detect serological evidence of recent infection with $M$. hominis or T-strain mycoplasmas in any of the patients studied. Low stable titres of MI antibody to the T-960 strain of T-strain or to the DC-63 or PG-21 strains of $M$. hominis were detected in sera from some of the patients, but such antibody did not appear to be related to the type of urethritis the patient had experienced. Furtherınore, we could not detect MI antibody to the homolog ?us mycoplasma isolate in acute or convalescent scra from thirteen patients infected with $\mathrm{T}$-strain myci plasma and five patients infected with $M$. hominis. In previous studies using the MI technique, only two of 31 NGU patients were found to have a 4-fold or greater rise in antibody titre to a T-strain mycoplasma (Purcell and others, 1966a; Ford, 1967).

TABLE IV Mycoplasmas and chlamydiae in urethritis

\begin{tabular}{|c|c|c|c|c|c|}
\hline \multicolumn{2}{|l|}{ Type of urethritis } & $\frac{N G U}{36}$ & $\frac{P G U}{9}$ & $\frac{G U}{32}$ & $\frac{\text { Total }}{77}$ \\
\hline \multirow[t]{4}{*}{ Organisms isolated } & $\begin{array}{l}\text { Chlamydiae only } \\
\text { T-strain mycoplasma }\end{array}$ & 6 & 1 & 5 & 12 \\
\hline & only & 16 & 3 & 8 & 27 \\
\hline & $\begin{array}{l}\text { M. hominis only } \\
\text { Chlamydiae + }\end{array}$ & 8 & 1 & 5 & 14 \\
\hline & $\begin{array}{c}\text { T-strain } \\
\text { Chlamydiae + }\end{array}$ & 2 & 0 & 0 & 2 \\
\hline
\end{tabular}


More recently, Jansson and others (1971), using a passive haemagglutination technique, demonstrated a 4-fold or greater rise in titre of antibody to one strain of T-strain in seven of $54 \mathrm{NGU}$ patients tested; none of the patients showed a rise in titre when a different $T$-strain was used as the antigen. Such a finding suggests that the metabolic inhibition technique for measuring antibody may be insufficiently sensitive to demonstrate a serological response or that infection of the urethra by $M$. hominis or $T$-strain mycoplasmas may be too superficial to stimulate a serum MI antibody response. However, the metabolic inhibition technique has proved quite sensitive for the detection of antibody to $M$. pneumoniae or $M$. hominis after infection with these organisms, and the development of serum MI antibody to these two mycoplasmas has been demonstrated even after relatively mild and superficial upper respiratory infections (Steinberg, White, Fuld, Gutekunst, Chanock, and Senterfit, 1969; Purcell and others, 1967). Therefore, it is likely that urethritis caused by $M$. hominis or T-strain mycoplasmas would result in the development of serum MI antibody, at least to the homologous strain, and failure to find such antibody may therefore constitute further evidence that these mycoplasmas were not aetiologically related to the NGU or PGU in the patients in this study.

It is noteworthy that no association between the recovery of mycoplasmas and that of chlamydiae was found in this study. Such a finding is in agreement with that of Dunlop, Hare, Jones, and TaylorRobinson (1969). However, Ford (1968) found an inverse relationship between the recovery of $T$-strain mycoplasmas and that of chlamydiae in a small number of patients with NGU. Further study will be required to resolve these differences. A detailed analysis of the chlamydiae isolated from the patients in this study has been reported previously (Philip and others, 1971).

The aetiology of non-gonococcal urethritis has been disputed for many years. The favourable response of this disease to treatment with broadspectrum antibiotics, but not penicillin or other cell wall-inhibiting antibiotics (Lassus, Perko, Stubb, Mattila, and Jansson, 1971), coupled with the recovery of $\mathrm{T}$-strain mycoplasmas approximately twice as frequently from NGU patients as from controls, has made the $T$-strain a likely candidate for the role of causative agent of this apparently venereally spread disease. However, the finding of $T$-strains in 20 to 48 per cent. of normal control populations (Haas and others, 1971), and the failure to demonstrate an antibody response to $\mathrm{T}$-strains in patients with NGU has made it impossible to definitely establish an aetiological role for T-strain mycoplasmas in NGU. The present study demonstrates that there is apparently nothing serologically unique about the T-strains or $M$. hominis mycoplasmas recovered from patients with NGU or PGU. Resolution of the problem of the aetiology of NGU and PGU must await the development of more sensitive serological techniques for measuring antibody to mycoplasmas in human sera, or the development of new media and culture techniques with which to attempt the isolation of "new" genital agents.

\section{Summary}

$M$. hominis and T-strain mycoplasmas were isolated from patients with NGU, PGU, and GU. Antigenic characterization of the recovered organisms demonstrated diverse patterns of cross-reactivity to antisera prepared to four strains of $M$. hominis and thirteen $\mathrm{T}$-strain mycoplasmas. There was no evidence of serological response in the patients to either homologous or related mycoplasmas.

The authors are indebted to Dr. C. Wendell Freeman, Chief of the Venereal Disease Control Division, whose active interest made this study possible, and Mrs. Corine Wilson and the staff of the Northwest Central Venereal Disease Clinic, D.C. Department of Health, for their assistance in collecting clinical information and laboratory specimens from the patients in this study. They are also grateful for the technical assistance of Mrs. Louise Kendrick and Mr. Jose Valdesuso.

\section{References}

Black, F. T., and RASMussen, O. G. (1968) Brit. F. vener. Dis., 44, 324

Chanock, R. M., Hayflick, L., and Barile, M. F. (1962) Proc. nat. Acad. Sci. (Wash.), 48, 41

CsonkA, G. W., Williams, R. E. O., and Corse, J. (1966) Lancet, 1, 1292

Del Giudice, R. A., Robillard, N. F., and Carski, T. R. (1967) F. Bact., 93, 1205

Dunlop, E. M. C., HaRe, M. J.: Jones, B. R., and Taylor-Robinson, D. (1969) Brit. F. vener. Dis., 45, 274

Edward, D. G. ff., and Fitzgerald, W. A. A. (1952) Vet. Rec., 64, 395

and FrEUNDT, E. A. (1956) f. gen. Microbiol., 14, 197

FoRD, D. K. (1967) Ann. N.Y. Acad. Sci., 143, 501 (1968) Canad. med. Ass. F., 99, 900 and DuVernet, M. E. (1966) F. Bact., 91, 899

- RAsmussen, G., and Minken, J. (1962) Brit. $\mathcal{f}$. vener. Dis., 38, 22

FowleR, W., and LeEming, R. J. (1969) Ibid., 45, 287

HaAs, H., Dorfman, M. L., and Sacks, T. G. (1971) Ibid., 47, 131

Hare, M. J., Dunlop, E. M. C., and Taylor-Robinson, D. (1969) Ibid., 45, 282 
Hayflick, L., and Chanock, R. M. (1965) Bact. Rev., 29, 185

INGHam. H. R., MacFarlane, W. V., HaLe, J. H., Selkon, J. B., and Codd, A. A. (1966) Brit. F. vener. Dis., 42, 269

Jansson, E., Lassus, A., StubB, S., and TuURI. S. (1971) Ibid., 47, 122

Lassus, A., Perko, R. L., Stubb, S., Mattila, R., and JANSSON, E. (1971) Ibid., 47, 126

Philip, R. N., Hill, D. A., Greaves, A. B., Gordon, F. B., QuAN, A. L., GerLoff, R. K., and ThOMAS, L. A. (1971) Ibid., 47, 114

Purcell, R. H., Chanock, R. M., and Taylor-Robinson, D. (1969) 'Serology of the mycoplasmas of man' in 'The Mycoplasmatales and the L-phase of Bacteria', ed. L. Hayflick, p. 221. North Holland Publishing Co., Amsterdam

-, Taylor-Robinson, D., Wong, D., and Chanock, R. M. (1966a) F. Bact., 92, 6

,,,$----(1966 \mathrm{~b})$ Amer. F. Epidemiol., 84, 51

, Wong, D., Chanock, R. M., Taylor-Robinson, D., Canchola, J., and Valdesuso, J. (1967) Ann. N.Y. Acad. Sci., 143, 664

ShePARD, M. C., (1959) Urol. Int. (Basel), 9, 252 (1966) Brit. F. vener. Dis., 42, 21
-, Alexander, C. E., Lunceford, C. D., and CampBeLl, P. E. (1964) f. Amer. med. Ass., 188, 729

SMITH, W. E. (1942) F. Bact., 43, 83

SteinberG, P., White, R. J., Fuld, S. L., Gutrkunst, R. R., Chanock, R. M., and Senterfit, L. B. (1969) Amer. F. Epidemiol., 89, 62

Taylor-Robinson, D., Addey, J. P., Hare, M. J., and Dunlop, E. M. C. (1969) Brit. F. vener. Dis., 45, 265

, Somerson, N. L., TuRner, H. C., and Chanock, R. M. (1963) f. Bact., 85, 1261

Mise en évidence de mycoplasmes isolés chez des malades atteints d'urétrite

\section{SOMMAIRE}

$M$. hominis et des mycoplasmes de souches $\mathrm{T}$ furent isolés chez des malades atteints d'urétrite non gonococcique, d'urétrite pseudo-gonococcique et d'urétrite gonococcique. La caractérisation antigénique des organismes obtenus présente divers types de réactivité croisée vis-à-vis d'antisérums préparés à l'aide de 4 souches de $M$. hominis et de 13 mycoplasmes souche $T$.

Il n'y eut pas d'évidence de réponse sérologique chez les malades aux mycoplasmes homologues ou apparentés. 